\title{
Patient safety in surgical centers - An integrated review
}

\begin{abstract}
The aim of this study was to analyze patient safety in a surgical center by an integrated review method. A review of current literature led to the conclusion that instituting a safe surgical program, adequately equipping the surgical teams and encouraging good practices in the operating room can significantly improve the outcomes in surgical patients.
\end{abstract}

Keywords: patient safety; perioperative nursing; perioperative care
Volume 9 Issue I - 2017

\author{
Oliveira Junior, Nery José de Silva, Rodrigo \\ Barreto da Becker, Gabriel Rosner \\ Master in Nursing, Lecturer at the FADERGS University Center, \\ Member of the Center for Nursing Management Studies \\ (NEGE), Brazil

\begin{abstract}
Correspondence: Nery José de Silva, Master in Nursing, Lecturer at the FADERGS University Center, Member of the Center for Nursing Management Studies (NEGE), Avenida Jacui 638/3।I, Cristal, 908I0-150, Porto Alegre, RS, Brazil, Tel (5I) 21113966, Email nery.oliveirajr@gmail.com
\end{abstract}

Received: October 27, 2017 | Published: November 15, 2017

\section{Introduction}

Despite recent global initiatives to promote patient safety in surgical care settings, there is still scope to improve patient care at all levels. It is estimated that approximately 20 million people undergo surgery every year in the United States alone and an estimated 234 million surgeries worldwide annually. This works out to nearly one surgery per 25 population..$^{1-3}$ Concerns about patient safety during surgery began during the early $19^{\text {th }}$ century before the discovery of anesthesia. Safety issues became the focus of discussion and concern, leading to standardized protocols with respect to monitoring, morbidity and mortality analysis in all health institutions. This had an positive impact and a significant reduction in adverse events in the perioperative period. ${ }^{4}$ The National Patient Safety Program adopted in Brazil established the standards and strategies for patient safety in surgical care settings. ${ }^{5,6}$

There is however, still a dearth in the investment by many institutions to support, promote and strengthen the safety culture. A committed and responsible professional approach is necessary to ensure compliance with the recommended protocols, and ensure a multidisciplinary, integrated team work to maximize patient safety. ${ }^{7}$ We are not satisfied with just lip service but expect effective and relevant strategies to minimize human errors in the institutions that provide health care.

The use of the Safe Surgery Checklist is one of the interventions adopted by hospital institutions to ensure that surgical interventions are done for the correct patient, correct part of the body and in the correct manner, as stated by the Joint Commission International. ${ }^{8}$ The Safe Surgery Checklist protocol must be adhered to by all surgical and allied professionals to ensure best outcomes. The theatre nurse must be dynamic and constantly alert to ensure that nursing interventions to are closely supervised in order to minimize and prevent complications arising from the anesthetic and surgical procedures. Ensuring maximum patient safety is a requirement of the Hospital Accreditation programs. This study had the similar objective while analyzing the available scientific literature with regards to patient safety in various surgical centers.

\section{Methodology}

An integrative review of the available scientific literature on the subject of patient safety in the perioperative period ensures a more comprehensive analysis of data, allowing for the synchronous inclusion of experimental and non-experimental studies and permitting a greater understanding of health issues concerned. ${ }^{9}$ Inclusion criteria were national and international articles, free access databases, articles published between January 2012 and July 2016. The exclusion criteria were articles that were not compatible with the objective of this integrative review and those not indexed. Six aspects were covered in detail. The first addressed the published scientific evidence concerned with patient safety in various surgical centers. The second phase analyzed the the LILACS (Latin American and Caribbean in Health Sciences) and SciELO (Scientific Electronic Library Online) databases using the descriptors "Patient Safety", "Perioperative Care", "Perioperative Nursing", "Patient Safety", "Perioperative Care", "Perioperative Nursing", "Patient Safety", "Perioperative Care" and "Perioperative Nursing" In English, Spanish and Portugese language publications worldwide. In the third phase, the information extracted was subject to an integrative review with elaboration of a database with pertinent information. In the fourth and fifth phases, the articles were re-evaluated and the core recommendations discussed with experts. In the sixth and final stage, the articles were analyzed and conclusions drawn, fully respecting matters pertaining to copyrights and author privacy aspects.

\section{Results}

After a thorough evaluation, eight published papers related to the topic of patient safety in a surgical center were shortlisted (Table 1 \& 2).

\section{Discussion}

The first study pertains to the perception by health professionals of the safety environment in a surgical center in Brazil. The authors used an adaptation of the Safety Attitudes Questionnaire / Operating Room (SAQ / OR) to monitor, evaluate and stratify the risk of adverse events in the operating room. The rest address the importance of postoperative visit as a strategy for evaluating the quality of nursing care in the peri 
operative period and the importance of implementing and applying a safe surgery checklist for both nursing and surgical professionals to improve outcomes. One retrospective study investigates adverse surgical events in a private outpatient surgical center.

In 2008, The World Health Organization lunched the "Safe Surgeries Saves Lives" program with recommendations to raise the standards and quality of care globally by focusing attention on the fundamentals practices of surgical safety. ${ }^{3}$ The report was formulated after studying eight premier institutions located in Canada, Jordan, India, Tanzania, the Philippines, England, New Zealand and the United States. This study revealed that the application of the safe surgery checklist almost doubled the chances of correctness of surgical procedures and interventions, significantly reducing mortality and complications by $47 \%$. This improvement was effected by changes in the protocols followed and improvement in attitudes within the surgical team and improved interpersonal communication.

Table I Number of articles found, pre-selected and selected in the databases as cross-descriptors

\begin{tabular}{|c|c|c|c|c|}
\hline Databases & search strategy & Results & Repeat articles & Selected articles \\
\hline \multicolumn{5}{|l|}{ In English } \\
\hline & Patient Safety AND Perioperative Care & 14 & 02 & 01 \\
\hline \multirow[t]{3}{*}{ LILACS } & Patient Safety AND Perioperative Nursing & 11 & 10 & 00 \\
\hline & Patient Safety AND Perioperative Care AND Perioperative Nursing & 07 & 06 & 00 \\
\hline & Patient Safety AND Perioperative Care & 00 & 00 & 00 \\
\hline \multirow[t]{3}{*}{ SciELO } & Patient Safety AND Perioperative Nursing & 04 & 04 & 00 \\
\hline & Patient Safety AND Perioperative Care AND Perioperative Nursing & 00 & 00 & 00 \\
\hline & Subtotal & 36 & 21 & 01 \\
\hline \multicolumn{5}{|l|}{ In Spanish } \\
\hline & Patient Safety AND Perioperative Care & 02 & 02 & 00 \\
\hline \multirow[t]{3}{*}{ LILACS } & Patient Safety AND Perioperative Nursing & 10 & 08 & 00 \\
\hline & $\begin{array}{l}\text { Patient Safety AND Perioperative Care AND } \\
\text { Perioperative Nursing }\end{array}$ & 02 & 02 & 00 \\
\hline & Patient Safety AND Perioperative Care & 00 & 00 & 00 \\
\hline \multirow[t]{3}{*}{ SciELO } & Patient Safety AND Perioperative Nursing & 01 & 01 & 00 \\
\hline & Patient Safety AND Perioperative Care AND Perioperative Nursing & 00 & 00 & 00 \\
\hline & Subtotal & 15 & 14 & 00 \\
\hline \multicolumn{5}{|c|}{ In Portuguese } \\
\hline & Patient Safety AND Perioperative Care & 08 & 01 & 02 \\
\hline \multirow[t]{3}{*}{ LILACS } & Patient Safety AND Perioperative Nursing & 11 & 01 & 05 \\
\hline & Patient Safety AND Perioperative Care AND Perioperative Nursing & 07 & 03 & 00 \\
\hline & Patient Safety AND Perioperative Care & 00 & 00 & 00 \\
\hline \multirow[t]{4}{*}{ SciELO } & Patient Safety AND Perioperative Nursing & 04 & 04 & 00 \\
\hline & Patient Safety AND Perioperative Care AND Perioperative Nursing & & & \\
\hline & Subtotal & 30 & 09 & 07 \\
\hline & TOTAL & 81 & & 08 \\
\hline
\end{tabular}

Table 2 Selected scientific papers

\begin{tabular}{ll}
\hline Titles of studies & Year \\
\hline Patient safety in the surgical environment: translation and cultural adaptation of a validated instrument. & 2016 \\
Validation of surgical checklist for prevention of surgical site infection. & 2015 \\
Analysis of adverse events in an outpatient surgical center. & 2015 \\
Prevalence of undamaged incidents and adverse events in a surgical clinic. & 2015 \\
Surgical safety checklist Considerations from the institutional micropolitics. & 2015 \\
Analysis of the registry and content of checklists for safe surgery. & 2014 \\
Checklist of safe surgery: analysis of the safety and communication of the teams of a school hospital. & 2013 \\
The post-operative visit as a strategy for evaluating the quality of nursing care in the trans-operative period. & 2013 \\
\hline
\end{tabular}

The experience of all the authors studied revealed that an overall commitment to patient safety backed by management support and resources resulted in better patient safety due to greater investments in monitoring and surgical equipments, and also improved manpower selection and training. ${ }^{10}$ Human factors are of paramount importance in patient care as human errors can adversely impact patient outcomes. Skills, dedication, alertness and attention to asepsis are vital aspects. Fatigue, overwork, poor remuneration and work environment can compromise standards of care. ${ }^{11}$

The literature analyzed highlight the importance of a safety culture and climate in the Operating Room (OR) and stress the importance of the existing safety culture as evaluated by psychometric questionnaires. These measure the attitudes and perceptions about patient safety by professionals within hospital organizations. It also reflects the value based actions taken by the organization with respect to perioperative safety measures. ${ }^{12}$ The major problems related to checklist adherence were related to the phases before anesthetic induction and before the surgical incision. These gray areas must, therefore, be receive greater focus by the surgical team during the process implementation period. Also, in five British hospitals, $40 \%$ of the staff were absent at the check huddle and, more importantly, there was no time allotted to check the safe surgery checklist in $70 \%$ of medical institutions 
studied. In ten hospitals investigated, there was poor compliance and adherence to take time off for check list verification by senior surgical staff, reflecting negatively on the rest of the team. ${ }^{13}$

Introduction of the preoperative checklist is an important step towards a new safety culture in the OR. A study of the safety and communication analysis of the teams showed that the surgical teams were willing to participate in this new culture, and $100 \%$ of the research subjects responded that they were in favour of incorporating the drill as it enhanced patient safety, prevented catastrophes and adverse events, eliminated human and technical errors and minimized litigation. ${ }^{14}$ There is a need to reorient and motivate the surgical team members to take time off to verify the check list on patient arrival. There is also a requirement to identify and understand the factors that hinder the integral verification and highlight the ethical and legal aspects involved in professional performance. ${ }^{15}$ The verification aims at preventing adverse events and guaranteeing the safety of the surgical patient, based on objectives established by the WHO.

Communication within the operating room remains largely inadequate and the checklist approach can detect situations where the surgeon in charge of the patient may not be fully aware or informed of the details of the surgical procedure planned. Competent communication facilitates humanization and constructs care in a transformative way, directly linked to the interaction between patients and work colleagues. ${ }^{16}$ Inadequate or improper communication between the nursing team members and the medical staff is a major cause implicated in surgical adverse events. Accurate and effective communication among medical professionals is the key to preventing this. The importance of this finding is confirmed by data from the event report of an American accreditation program, where 843 events were recorded and, in the root cause analysis, communication problems were reported in $533(63.2 \%){ }^{17}$

The surgical center is configured as a high stress environment Inability to cope with high volume workload and turnover can precipitate confusion and hostility among senior faculty members. This type of behaviour can intimidate the nursing staff and cause them to withhold important patient related matter for fear of reprisals or retaliation. The safe surgery checklist overcomes this problem as every variable is comprehensively covered, leaving no room for ambiguity at any stage of patient transit. ${ }^{18}$

The drill of filling check lists is considered an onerous task by many team members. This has been validated in the Spanish studies that observed completion of check lists by 90 and $100 \%$ of the nursing staff. The figures were alarming in other members with only $42 \%$ of anaesthesiologists and $21 \%$ of surgeons bothering to fill the lists pertaining to their areas. The nursing co ordinator was considered the best candidate to oversee that the check lists were properly filled in by all members of the surgical team. ${ }^{19}$

The checklist approach to maximize patient safety in the OR is, without doubt, the most important tool to prevent human errors and failures. There is a great deal of patient to patient variability in the health care sector and there are wide deviations from the norm in many cases. Again, each institution has its own protocol in the work up to surgery and postoperative care. The surgical team must be able to comprehend this fact and try to evolve their own systematic protocols within the existing resources available to them. They can deliberate over these variables and modify the check lists without compromising safety issues. Some degree of flexibility in the check list approach can be evolved to facilitate each institution, if inescapable.

\section{Conclusion}

The safe surgery checklist is a fundamental tool in the surgical process. It addresses all aspects of issues pertaining to patient safety to ensure a satisfactory outcome every time. It helps minimize human error and promotes client satisfaction. All levels of the hospital management must support this approach and also undertake measures to decrease workplace stress, improve human interactions to ensure better communication across the members of the surgical team and also to ensure good infra structure and training programs to improve skills and cut costs. The content of the documents analyzed allows us to conclude that instituting a safe surgery program, equipping the teams and encouraging the proper practice of the model, consistent with the reality of each institution, is the correct path to success in safety with the surgical patient. This study could guide activities aimed at promoting safety culture and perception of health professionals, leaders and managers regarding patient safety, as well as being a parameter in relation to completing the checklist for other investigations.

\section{Acknowledgments}

None.

\section{Conflicts of interest}

The authors declare no conflicts of interest.

\section{Funding}

None.

\section{References}

1. Haynes AB, Weiser TG, Berry WR, et al. Safe Surgery Saves Lives Study Group. A surgical safety checklist to reduce morbidity and mortality in a global population. N Engl J Med. 2009;360(5):491-499.

2. Wachter RM. Compreendendo a segurança do paciente. 2nd edn, AMGH, Porto Alegre, Brazil. 2013.

3. World Health Organization. Safe surgery saves lives frequently asked questions. 2009

4. Joint Commission International. National patient safety goals effective. 2013

5. Ministério da Saúde (BR), Portaria 529 de 01 de abril de 2013 Programa Nacional de Segurança do Paciente (PNSP). Ministério da Saúde, Brasília. 2013

6. Haynes AB, Weiser TG, Berry WR, et al. Changes in safety attitude and relationship to decreased postoperative morbidity and mortality following implementation of a checklist-based surgical safety intervention. BMJ Qual Saf. 2011;20(1):102-107.

7. Cruz YL, Algonso PM, Pérez ACD. Seguridad del paciente en la cirugía refractiva con láser. Revista Cubana de Oftalmología, La Habana. 2012;25(1) [10 telas].

8. Oliveira Jr NJ. Segurança do paciente:o checklist da cirurgia segura em um centro cirúrgico ambulatorial. (Dissertação). Universidade Federal do Rio Grande do Sul, Porto Alegre, Brazil. 2015.

9. Saraiva EL, Sousa CS. Pacientes críticos na unidade de recuperação pós-anestésica:revisão integrativa. Rev SOBECC. 2015;20(2):104-112.

10. Marinho MM, Radünz V, Barbosa SFF. Avaliação da cultura de segurança pelas equipes de enfermagem de unidades cirúrgicas. Texto Contexto Enferm, Florianópolis. 2014;23(3):581-590. 
11. Lourenção DC, Tronchin DM. Segurança do paciente no ambiente cirúrgico:tradução e adaptação cultural de instrumento validado. Acta Paul Enferm. 2016;29(1):1-8.

12. Maziero ECS, Silva AEBC, Mantovani MF, et al. Adesão ao uso de um checklist cirúrgico para segurança do paciente. Rev Gaúcha Enferm. 2015;36(4):14-20.

13. Paranaguá TT, Bezerra AL, Silva AE, et al. Prevalência de incidentes sem dano e eventos adversos em uma clínica cirúrgica. Acta Paul Enferm. 2013;26(3):256-262.

14. Galvão CM. A prática baseada em evidências:uma contribuição para a melhoria da assistência de enfermagem perioperatória. Rev Latino-am Enfermagem setembro-outubro. 2002;10(5):690-695.

15. Manrique BT, Soler LM, Bonmati AN, et al. Segurança do paciente no centro cirúrgico e qualidade documental relacionadas à infecção cirúrgica e à hospitalização. Acta paul Enferm. 2015;28(4):355-360.
16. Tostes MFP, Haracemiw A, Mai LD. Lista de verificação de segurança cirúrgica:Considerações a partir da micropolítica institucional. Esc. Anna Nery. 2016;20(1):203-209.

17. Bohomol E, Tartali JA. Eventos adversos em pacientes cirúrgicos:conhecimento dos profissionais de enfermagem. Acta Paul Enferm. 2013;26(4):376-381.

18. Amaya MR, Maziero ECS, Grittem L, et al. Análise do registro e conteúdo de checklists para cirurgia segura. Esc Anna Nery. 2015;19(2):246-251.

19. Xavier T, Silva MF, Frias TFP. Postoperative visit as a strategy for assessment of nursing care quality in intraoperative. Revista de Pesquisa:Cuidado é Fundamental Online. 2014;6(3):1139-1151. 